\title{
Pathology of the Fetal Neck
}

\author{
Radu Vladareanu, Mona Zvanca, Cristian Andrei
}

\section{ABSTRACT}

Fetal neck is the site of important pathological changes, related to genetic, cardiovascular, lymphatic, endocrine systems.

Among the main neck pathology are fetal hygroma, goiter, teratoma/sarcoma, hemangioma/lymphangioma. Posterior anomalies of the fetal neural tube, such as occipital myelomeningocele or iniencephaly may also be included in this area.

Fetal hygroma is the main pathology, probably related to abnormal development of the lymphatic drainage system. There is a large spectrum of the disease, from enlarged nuchal translucency to generalized edema. Enlarged nuchal translucency is often associated with aneuploidy, particularly trisomy 21 and Turner syndrome (monosomy X). However, the pathophysiology is different for the two aneuploidies. On the diagnostic side, cystic hygromas consist of large single or multilocular fluid-filled cavities, which are usually easily identified during first trimester ultrasound examination. About one-third of euploid fetuses with first trimester septated cystic hygromas have major structural anomalies. In contrast, structural anomalies are detected in only 4 to $10 \%$ of euploid fetuses with enlarged nuchal translucency.

Enlargement of fetal thyroid gland is accompanied by increased or decreased level of thyroid hormones (hyper or hypothyroidism), but the thyroid function may also be normal. The physiopathology of fetal and neonatal goiter is complex. Causes of fetal goiter include inborn errors of thyroid hormone production, transplacental passage of maternal antibodies, maternal ingestion of antithyroid drugs and other goitrogens, thyroid tumors. Detection of the fetal goiter is facilitated by the associated maternal history, present in most of the cases. By definition, goiter means enlargement of the thyroid gland above the 95th centile of the normal range. Reliable and objective data about fetal thyroid function involves an invasive testing.

Teratomas are large mixed tumors arising from the neck region. Teratomas are cystic, semicystic or solid tumors. They develop from all three germ cell layers. Cervical teratomas are detected antenatally in most cases, as they are large size tumors.

Hemangiomas and lymphangiomas are tumors derived from the endothelial tissue of blood vessels or lymphatic vessels. They may develop anywhere in the body, but in the antenatal life and the first years they show a predisposition for the head, neck and axillar area.

Regarding the occipital encephalocele and iniencephaly, even though they represent major anomalies that affect he cervical and cephalic area, from a developmental point of view they are part of the neural tube defects spectrum and should be considered as such especially from a prognosis point of view.

Keywords: Fetal neck, Hygroma, Fetal goiter, Fetal hypothyroidism, Neck teratoma.

How to cite this article: Vladareanu R, Zvanca M, Andrei C. Pathology of the Fetal Neck. Donald School J Ultrasound Obstet Gynecol 2012;6(1):55-65.

Source of support: Nil

Conflict of interest: None declared

\section{INTRODUCTION}

\section{Embryological Development}

The development of the fetal neck starts between the fourth and the fifth week with the presence of four pairs of branchial arches. These represent bars of mesenchymal tissue that are separated by four paired clefts and pouches. At the end of the fourth week, the stomodeum (rudimentary mouth) is formed at the center of the face and is surrounded by the first pair of branchial arches.

The first pharyngeal pouch gives rise to the eustachian tube, middle ear and mastoid cells, as part of the temporal bone, the maxilla and the mandible, including the premaxilla and zygoma.

The second pouch forms the supratonsillar fossa.

The third pouch develops into the thymus gland and upper parathyroid glands.

The fourth pouch gives rise to the lower parathyroid gland and part of the thyroid gland.

Each arch contains neural crest cells, which contribute to the skeletal development. The mesoderm of the arches results in the musculature of the face and neck.

\section{ABNORMAL DEVELOPMENT OF FETAL NECK}

\section{Hygroma}

The latin word hygroma is translated as moist tumor. Cystic hygroma, as it is often called, represents not a tumor, but an anomaly of the lymphatic drainage into the venous system, which leads to the accumulation of lymph in the jugular lymphatic sacs of the cervical region. The anomaly is visible from the first trimester and it represents the end of the spectrum of the increased nuchal translucency. Cystic hygroma was divided into nonseptated (simple) and septated, with a presumably worse prognosis in the latter case. ${ }^{1}$ However, with the improving resolution and the increasing quality of the image offered by the advance of the ultrasound machines, it has become clear that all nuchal translucencies have visible septations. ${ }^{2}$ Therefore, this classification has been abandoned.

Abnormal lymphatic development in the fetal neck could lead to distension of the jugular venous sacs, an accumulation of fluid in the nuchal region and retrograde increase in venous pressure. This hypothesis is supported by the observation that reversed or absent ductus venosus 
flow during atrial contraction is observed in these fetuses. ${ }^{3}$ Eventual recanalization or formation of collaterals may explain the transient nature of abnormal ductus venosus waveforms and nuchal edema.

Enlarged nuchal translucency is also an important marker for congenital heart disease. Although nuchal edema in fetuses with heart defects was initially thought to be related to impaired atrial contraction, reduced myocardial compliance or cardiac failure, studies have not supported these mechanisms. ${ }^{4}$ No differences in intracardiac flow velocities in normal fetuses and those with enlarged nuchal translucency have been identified. ${ }^{5}$ Changes in the carotid artery, jugular vein or ductus venosus Doppler velocimetry are also not significantly related to nuchal translucency. ${ }^{6}$ Pericardial, pleural and peritoneal fluid (ascites) are frequent findings in fetuses with cardiac decompensation, but are rare in fetuses with enlarged nuchal translucency.

Enlarged nuchal translucency is often associated with aneuploidy, particularly trisomy 21 and Turner syndrome (Monosomy X). ${ }^{7}$ The pathophysiology is different for the two aneuploidies. In trisomy 21, the collagen content of the dermis is abnormal; its hydrophilic properties may lead to the accumulation of subcutaneous fluid. By comparison, fetuses with Turner syndrome often have lymphatic dysplasia. These fetuses are also at risk for narrowing of the aortic isthmus and widening of the ascending aorta, which may lead to overperfusion of the head and neck, thus contributing to the development of subcutaneous edema. Nuchal translucency may regress, if these connections are established later in gestation.

\section{Incidence}

Even though it cannot be considered pathology in itself, cystic hygroma is the most common cervical mass detected antenatally. The incidence varies with gestational age. In the first trimester, the overall prevalence of cystic hygromas is about 1 in 100 fetuses. ${ }^{1}$

\section{Diagnosis}

Cystic hygromas consist of large single or multilocular fluidfilled cavities, which are usually, easily identified during first-trimester ultrasound examination. They tend to be largest in the nuchal region, but may extend along the entire length of the fetus. Multiple internal septae or trabeculae may be detected when imaging a cystic hygroma in multiple planes (Figs 1A to E). The distended jugular lymph sacs can sometimes be visualized on either side of the fetal neck.

With improvements in first-trimester imaging, the distinction between simple cystic hygroma and increased nuchal translucency has become less clear. Possible distinguishing features of cystic hygromas are that they tend to be larger, extend along the entire length of the fetus and are more likely to contain multiple septae, whereas nuchal translucency is often confined to the nuchal region between the occiput and upper spine. Regardless of the etiology, size appears to be the significant determinant of outcome for all nuchal fluid collections, irrespective of whether there are internal septations or the fluid envelops the entire length of the fetus. ${ }^{7}$
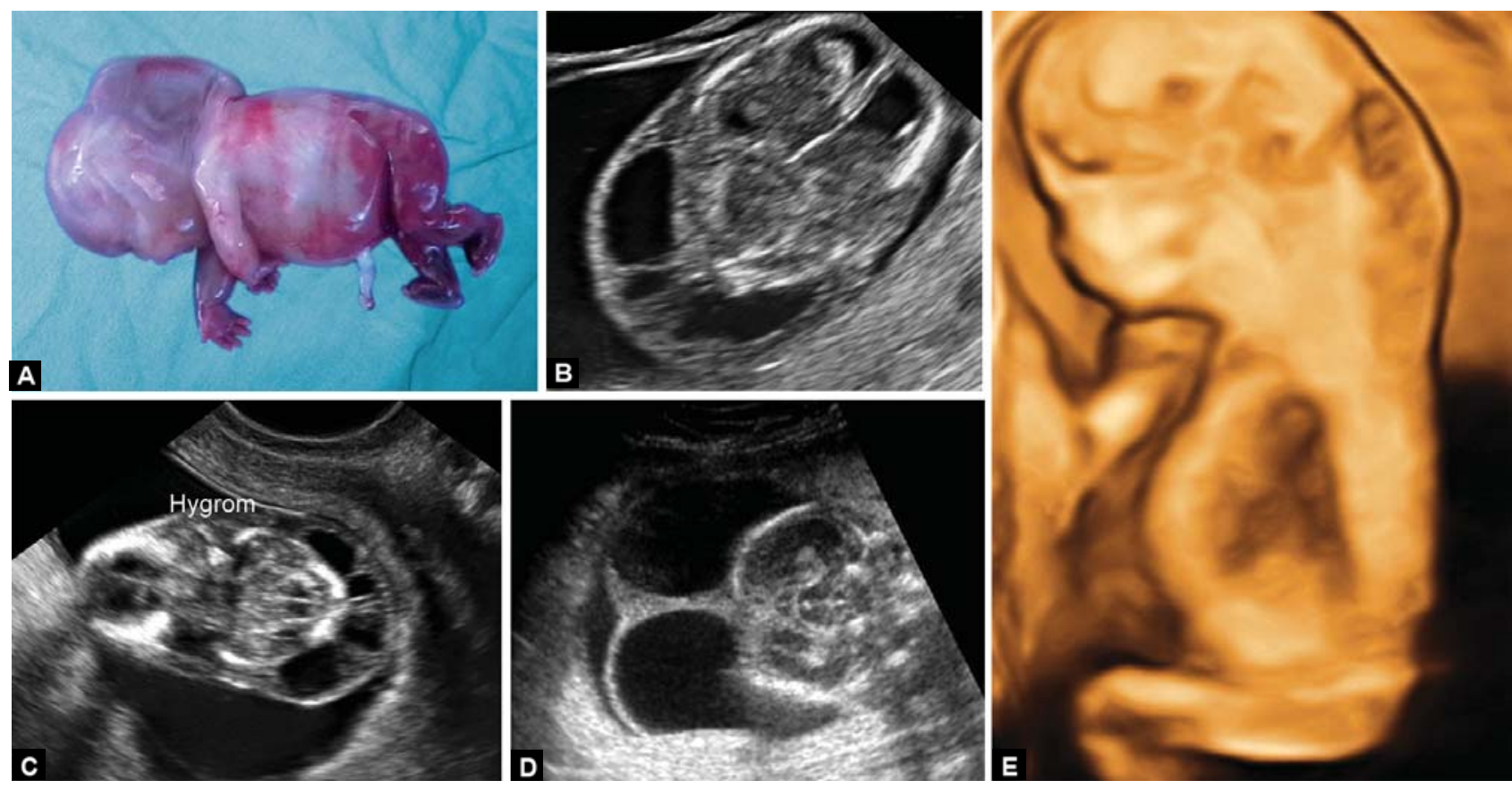

Figs $1 \mathrm{~A}$ to $\mathrm{E}$ : Cystic hygroma in a 16 weeks fetus with Turner syndrome: (A) Postabortum specimen; (B to D) Transverse section showing septations; (E) 3D rendering 


\section{Associated Anomalies}

About $50 \%$ of first trimester septated cystic hygromas occur in fetuses with trisomies, most commonly trisomy 21. Firsttrimester cystic hygromas are often associated with trisomies, whereas second- trimester cystic hygromas are often associated with Monosomy X. ${ }^{8-9}$

About one-third of euploid fetuses with first- trimester septated cystic hygromas have major structural anomalies. ${ }^{9}$ In contrast, structural anomalies are detected in only 4 to $10 \%$ of euploid fetuses with enlarged nuchal translucency. ${ }^{10}$ Associated malformations include cardiac defects, diaphragmatic hernia, renal anomalies, body stalk disruption and abdominal wall defects.

A significant discordance between nuchal translucency measurements in monochorionic twins is also predictive of twin-to-twin transfusion. About 25\% of monochorionic twins will have an intertwined discordance in nuchal translucency measurement of greater than 20\%; this subset of twins is more likely to develop twin-to-twin transfusion syndrome and experience early fetal demise. ${ }^{11}$

\section{Differential Diagnosis}

Other defects in the differential diagnosis of cystic hygroma include neural tube defects, such as a posterior encephalocele or cervical meningocele and cystic teratoma or hemangioma. These diagnoses can usually be excluded on high resolution transvaginal ultrasonography if an intact skull and spine are visualized, no solid component is seen in the cystic space, color-flow mapping shows a limited vascular supply, and internal septae are identified in the cystic mass.

\section{Prognosis}

Normal pediatric outcomes occur in 15 to 30\% of fetuses with first-trimester cystic hygromas, but the prognosis for a specific fetus depends upon the presence or absence of associated findings.

In the absence of aneuploidy or structural anomalies, the size of the first-trimester cystic hygroma appears to be the most important determinant of outcome. The larger the measurements of the nuchal translucency, the higher the risk of associated structural anomalies or intrauterine fetal demise. Even with a normal karyotype the possibility of an underlying rare genetic disorder should always be considered and a detailed anatomical survey should be carried out, including a specialist echocardiography.

Some studies have reported an increased prevalence (up to $8.7 \%$ ) of neurodevelopmental delay in children with a fetal history of increased nuchal translucency; however others have found no excess risk of developmental delay in children with normal karyotype and no congenital malformations in whom first-trimester nuchal thickening is resolved. ${ }^{12}$ Additional standardized pediatric evaluations and long-term neurodevelopmental follow-up studies are needed to better define these risks. Some genetic syndromes and conditions associated with developmental delay do not have any features amenable to prenatal diagnosis by ultrasound.

\section{Management}

Although the clinical implications may differ, the initial management of a pregnancy with a cystic hygroma and increased nuchal translucency is the same, which are as follows:

- Fetal karyotyping

- Comprehensive fetal anatomic survey

- Fetal echocardiography

- Serial assessment of fetal status.

Considering that cystic hygroma is a large nuchal translucency and the risk for associated chromosomal anomalies is about $50 \%$, it is reasonable to offer invasive testing in all the cases.

Early fetal anatomic evaluations can be performed using a combined approach, starting with an abdominal survey and assessing details through high-resolution transvaginal ultrasound; experienced ultrasonographers can detect many major malformations in the first trimester.

Fetal echocardiography may be attempted as early as the first trimester. According to the quality of image and the ultrasound findings, fetal heart may be reassessed at 14 , 16,18 or 20 weeks.

\section{Fetal Goiter}

Enlargement of fetal thyroid gland is accompanied by increased or decreased level of thyroid hormones (hyper or hypothyroidism), but the thyroid function may also be normal. The incidence of fetal goiter is better quantified for congenital hypothyroidism, which occurs in 1 out of 2,000 to 4,000 births, according to different statistics. ${ }^{13}$

Fetal production of thyroid hormones starts at 11 to 12 weeks, but the function of the hypothalamic-pituitarythyroid system is under maternal influence and it relies exclusively on the maternal supply of iodine, which is transferred into fetal circulation via a placental sodiumiodide $\left(\mathrm{Na}^{+} / \mathrm{I}^{-}\right)$symporter. A maternal iodine deficit will cause fetal goiter, but an iodine excessive diet may have the same effect. Fetal thyroid-stimulating hormone (TSH) receptors become responsive to TSH and TSH antibodies 


\begin{tabular}{|c|c|}
\hline $\begin{array}{l}\text { Inborn errors of thyroid } \\
\text { hormone production }\end{array}$ & Dyshormonogenesis \\
\hline $\begin{array}{l}\text { Transplacental passage of } \\
\text { maternal antibodies }\end{array}$ & $\begin{array}{l}\text { TSH-receptor blocking } \\
\text { antibodies } \\
\text { TSH-receptor stimulating } \\
\text { antibodies }\end{array}$ \\
\hline $\begin{array}{l}\text { Maternal ingestion of anti- } \\
\text { thyroid drugs and other } \\
\text { goitrogens }\end{array}$ & $\begin{array}{l}\text { Propylthiouracil } \\
\text { Methimazole or carbimazole } \\
\text { lodine and iodine-containing } \\
\text { drugs }\end{array}$ \\
\hline $\begin{array}{l}\text { Activating mutations of the } \\
\text { TSH receptor }\end{array}$ & $\begin{array}{l}\text { Congenital nonimmune } \\
\text { hyperthyroidism }\end{array}$ \\
\hline $\begin{array}{l}\text { Activating mutations of the } \\
\text { G protein alpha subunit }\end{array}$ & McCune-Albright syndrome \\
\hline \multicolumn{2}{|l|}{ Thyroid hemiagenesis } \\
\hline Thyroid tumors & \\
\hline
\end{tabular}

at 20 weeks. Therefore, fetal thyroid dysfunction can be detected only after this stage. Whereas maternal (thyroxine) T4 usually crosses the placenta in only minimal (but crucial for fetal development) amounts and TSH does not cross the placenta at all, maternal TSH receptor antibodies freely cross the placenta and may stimulate or, more rarely, inhibit fetal thyroid function. A normal fetal level of thyroid hormones is essential in the development of the brain and fetal hypothyroidism is the most common treatable cause of mental retardation. The IQ level tends to be inversely correlated to the age of the diagnosis of hypothyroidism. Fetal hyperthyroidism is equally dangerous, exposing the fetus to the risk of in utero death due to thyrotoxicosis or to long-term sequelae of an impaired thyroid function.

The physiopathology of fetal and neonatal goiter is complex. In 85\% of cases, it is sporadic and in the remaining 15\%, it has hereditary causes (Table 1 ).

\section{Inborn Errors of Thyroid Hormone Production}

Genetic defects in each step of thyroid hormone production (dyshormonogenesis) have been described. These defects are inherited as autosomal recessive traits. All result in varying degrees of hypothyroidism, and may be detected by newborn screening. ${ }^{14}$

The defects include the following:

- A defect in iodine transport because of a mutation in the $\mathrm{Na}^{+} / \mathrm{I}^{-}$symporter gene. ${ }^{15}$

- Iodine organification and coupling defects because of deficiency in the quantity or activity of thyroid peroxidase or in hydrogen peroxide generation.

- Pendred's syndrome is characterized by both goiter and sensorineural deafness (not caused by hypothyroidism).
These children have a mutation in a transport protein (pendrin) on chromosome 7q, which transports iodide into the exocytotic vesicles in which thyroid hormone is synthesized. This chloride-iodide transport protein functions in both the thyroid gland and inner ear. ${ }^{16}$

- Defects in thyroglobulin biosynthesis in which thyroglobulin production is decreased or the molecule is truncated or has amino acid substitutions within it. The result is decreased formation of T4 and triiodothyronine (T3) within the thyroglobulin. ${ }^{17}$

- Defects in iodotyrosine deiodinase result from mutations in the iodotyrosine dehalogenase 1 (DEHAL1) gene, so that the iodine contained in the iodotyrosine residues of thyroglobulin is lost.

These disorders account for approximately 10 to $15 \%$ of cases of congenital hypothyroidism. Elucidation of specific defects requires thyroid radionuclide imaging or ultrasonography, measurements of serum thyroglobulin and iodothyronines, and gene analysis.

\section{Transplacental Passage of Maternal Thyroid-reactive Antibodies}

Women with chronic autoimmune thyroiditis or Graves' disease may produce antibodies that cross the placenta, resulting in fetal and neonatal goiter and thyroid dysfunction, depending upon the type of antibody.

TSH-receptor blocking antibodies: Transplacental passage of TSH-receptor antibodies that block the action of TSH can cause fetal hypothyroidism, which is occasionally accompanied by goiter. These antibodies are detected in approximately 1:100,000 newborn infants. This disorder is confirmed by laboratory testing showing elevated thyrotropin-binding inhibitory immunoglobulin (TBII). The hypothyroidism and goiter in these infants are transient, typically resolving in 3 to 6 months, as the transplacentally acquired antibodies are cleared. ${ }^{18}$

TSH-receptor stimulating antibodies: Transplacental passage of TSH-receptor antibodies that mimic the action of TSH cause fetal and neonatal Graves’ hyperthyroidism and goiter. The mother may have had hyperthyroidism during the pregnancy, or she may have had it in the past and have been treated by thyroidectomy or radioactive iodine.

Neonatal Graves' disease occurs in approximately 1:25,000 neonates. Laboratory testing showing elevated thyroid stimulating immunoglobulin (TSI) in mother or neonate will confirm Graves' disease. Neonatal Graves' hyperthyroidism and goiter resolve in 3 to 6 months as the antibodies are cleared. 


\section{Maternal Ingestion of Antithyroid Drugs and Other Goitrogens}

The antithyroid drugs propylthiouracil, methimazole and carbimazole all cross the placenta and can cause fetal hypothyroidism and goiter. Other compounds that can cross the placenta and cause fetal hypothyroidism and goiter are iodine-rich drugs, such as expectorants, amiodarone and skin disinfectants.

\section{Activating Mutations of the TSH-receptor (Congenital Nonimmune Hyperthyroidism)}

Germline mutations of the TSH-receptor gene that result in constitutive activation of the receptor are a rare cause of diffuse goiter and hyperthyroidism, which may be present at birth or first become evident, years or even decades later. ${ }^{19}$ These mutations are inherited as autosomal dominant traits; as a result, there may be a family history of hyperthyroidism and goiter.

\section{McCune-Albright Syndrome}

Somatic mutations in the alpha subunit of the guanine nucleotide-binding protein ( $G$ protein) are present in the thyroid gland in infants and children with the McCuneAlbright syndrome. ${ }^{20}$ They are activating mutations and therefore result in thyroid hyperplasia or formation of nodules and, ultimately, in toxic nodular goiters. Other features of the syndrome, such as café-au-lait skin pigmentation, precocious puberty or polyostotic fibrous dysplasia, are usually present and provide clues to the underlying diagnosis. The hyperthyroidism is permanent and some form of thyroid ablation is indicated.

\section{Thyroid Hemiagenesis}

Thyroid hemiagenesis may cause unilateral goiter in neonates because of compensatory hypertrophy of the contralateral lobe.

\section{Diagnosis}

Detection of the fetal goiter is facilitated by the associated maternal history, present in most of the cases. Even though it is not part of the routine second-trimester examination, there are nomograms for the size of the thyroid gland starting with 16 weeks. ${ }^{21,22}$ This is particularly useful in fetuses with mild enlargement of the gland. Both the volume and the circumference of the gland have proven to have good correlations with the gestational age and biparietal diameter and there is a constant ratio between the thyroid volume and the estimated fetal weight throughout the gestation $\left(0.163+/-0.079 \mathrm{~cm}^{3} / \mathrm{kg}\right){ }^{22}$ Assessment of the thyroid gland size and structure should be done using both sagittal and transverse sections of the fetal neck (Figs 2A to C).

By definition, goiter means enlargement of the thyroid gland above the 95th centile of the normal range, irrespective of the considered parameter, volume or linear size. The sonographic appearance is solid, hypoechoic, but it may also have a cystic component. Previous studies have described an association between the pattern of the blood flow inside the thyroid gland and the level of the fetal thyroid hormones. ${ }^{23,24}$ By using color-flow mapping at a velocity of $13 \mathrm{~cm} / \mathrm{sec}$ the authors described that a Doppler signal that is detected throughout the entire gland is suggestive of fetal hyperthyroidism, whereas a blood flow confined to the periphery is indicative of fetal hypothyroidism. There are reports of glandular blood flow quantification using the vascularization indices and the vocal software. ${ }^{25}$

In the situation of a very large fetal goiter, the neck is usually hyperextended and it may be associated polyhydramnios. In such cases, there should be considered the possibility of airway obstruction with serious perinatal consequences.

Functional assessment of the fetal thyroid gland may be done through invasive methods, either amniocentesis or cord blood sampling. Indirect information about the status of the fetal metabolism may be given by the bone maturation and
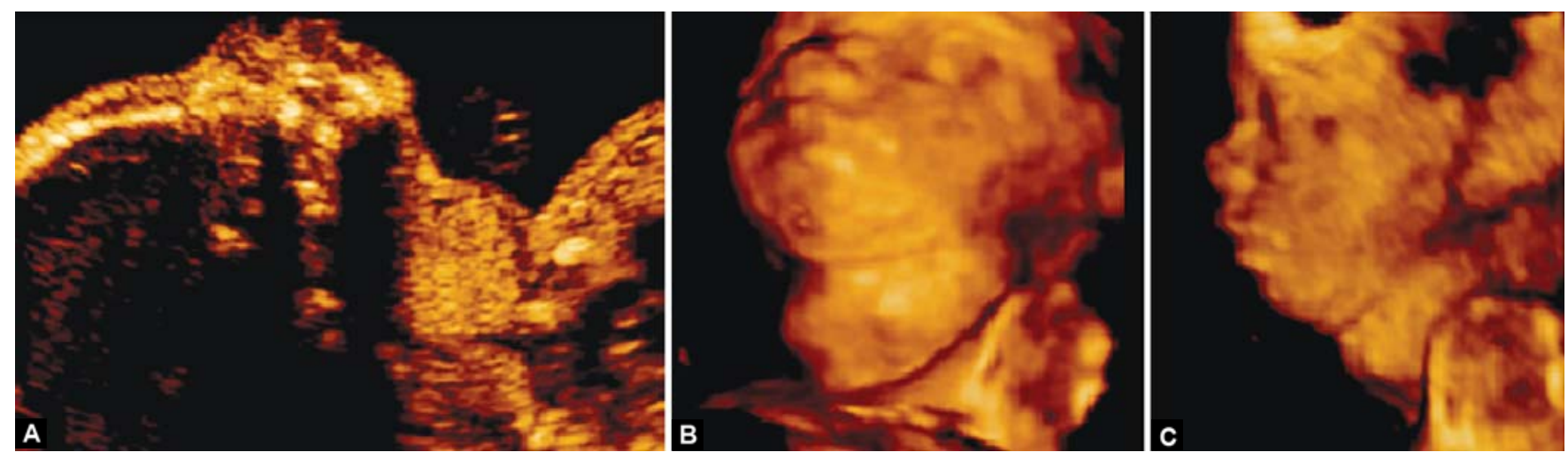

Figs 2A to C: Twenty-eight weeks fetus with goiter. (A) Fetal profile compared to; $(B$ and $C)$ 3D surface rendering mode show a clearly visible goiter 
the fetal heart rate and heart function. The distal femoral ossification center is undetectable before 28 weeks; it is dot-size at 32 weeks, smaller than $3 \mathrm{~mm}$ at 33 weeks. Accelerated bone maturation was defined as the presence of the distal femoral ossification center before 31 weeks of gestation, and delayed bone maturation was defined as the absence of the center after 33 weeks of gestation. ${ }^{26}$ Accelerated bone maturation is associated with an excessive amount of thyroid hormones.

Reliable and objective data about fetal thyroid function involve an invasive testing. Measurement of the TSH, free T3 and free T4 should be performed only using cord blood, as there is a poor correlation between the amniotic levels and the fetal metabolic status. The amniotic fluid may be, however, a good transport for therapeutic drugs. ${ }^{27}$

\section{Differential Diagnosis}

The goiter should be distinguished from other cervical pathologies as follows:

- Cervical teratoma: Rapidly growing tumor, mixed structure, solid-cystic, no association with maternal thyroid dysfunction

- Hemangioma/lymphangioma: Usually lateral mass of the neck, with a dominant cystic component.

\section{Associated Anomalies}

Congenital hypothyroidism appears to be associated with an increased risk of additional congenital malformations affecting the heart, kidneys, urinary tract, gastrointestinal and skeletal systems. ${ }^{28}$ Infants with congenital hypothyroidism and cleft palate may have a TTF-2 (FOXE1) gene mutation. ${ }^{29}$ Infants with persistent neurologic problems, including ataxia, are suspect for a NKX2-1 gene mutation. ${ }^{30}$

\section{Management}

Fetal hypothyroidism: The following instructions can be useful in the prevention, diagnosis and management of fetal hypothyroidism. ${ }^{31}$

- Adequate iodine intake should be ensured for all pregnant women (250 gm daily)

- For women with a personal or family history of thyroid disease, measure plasma TSH and free T4 levels before, at the beginning and during pregnancy

- On ultrasonography between 22 and 32 gestational weeks, measure fetal thyroid diameter and circumference: If above the 95th centile for gestational week, consider fetal thyroid disorder

- If thyroxine treatment is given to a pregnant woman, ensure adequate increase in dose throughout pregnancy
- If fetal goiter is documented, consider cordocentesis and fetal blood T4 and TSH level measurement, and intraamniotic thyroxine injections, if severe hypothyroidism is diagnosed.

Fetal hyperthyroidism: It may be treated safely and effectively by means of antithyroid drugs administered to the mother. ${ }^{32}$ The therapeutic level in fetal blood may induce maternal hypothyroidism. This is easily corrected by the addition of thyroxine. In pregnant women, propylthiouracil is preferred to methimazole or carbimazole because the latter has been associated with aplasia cutis congenita and other malformations. ${ }^{33}$

In pregnant women who are taking antithyroid therapy and/or who have positive results for TSI, monthly ultrasound imaging might be justified after 20 weeks of gestation to monitor whether evidence of thyroid dysfunction, including goiter, is developing in the fetus.

\section{Teratoma/Sarcoma}

Teratomas are large mixed tumors arising from the neck region. They are very rare, accounting for less than $0.1 \%$ of all neonatal neoplasms. ${ }^{34}$ The incidence varies from 1 in 20,000 to 1 in 40,000 live births, according to different studies. $^{35}$ Even though they are benign tumors, the associated mortality is, however, high because of immediate neonatal respiratory distress due to tracheal compression or compression of other critical structures of the neck. Some of these tumors may be malignant or may develop later into adult life.

Teratomas are cystic, semicystic or solid tumors. They develop from all three germ cell layers. Histologically, most of these tumors are composed of neural tissue (68\%). Thyroid tissue may be found inside the tumor mass or as a pseudocapsule. Malignant characteristics, invasive growth and metastatic spread are found more often in tumors developing in teenagers and adults. ${ }^{36}$

They may develop in the anterior or posterior triangle of the neck and they were subclassified into thyroid or cervical teratomas. This classification has no clinical significance and was abandoned. In almost all anteriorly located teratomas, a close relationship with the thyroid gland was observed. ${ }^{37}$

\section{Diagnosis}

Cervical teratomas are detected antenatally in most cases, as they are large sized tumors. When located in the anterior region they hyperextend in the fetal neck. Like most tumors of this type, due to the important blood supply, they have a fast growth rate. The mixed, semicystic structure is clearly visible on the antenatal ultrasound and makes the diagnosis 


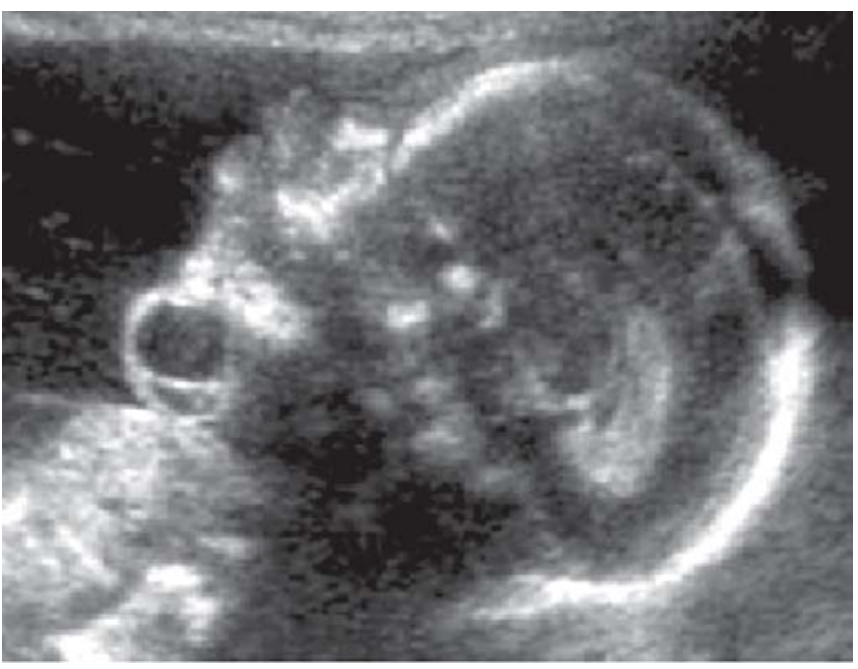

Fig. 3: Cervical teratoma located in the anterolateral region, with a mainly cystic component. The extended position of the neck is to be noted

easy (Fig. 3). Sometimes calcifications may be seen inside the tumor mass, which suggest the presence of high-density tissue, such as cartilage. The diagnosis may be as early as the first trimester. ${ }^{38}$

\section{Associated Anomalies}

Polyhydramnios may be associated due to esophageal obstruction and interference with the fetal deglutition. Deviation of the larynx and trachea results in compression of the esophagus and inhibits fetal swallowing. Hypoglossal nerve compression by the expanding tumor mass may add to the deglutition problem.

Pulmonary insufficiency may develop due to compression of a very large tumor on the thorax.

Chondromalacia is also reported as a result of the mass effect.

\section{Differential Diagnosis}

Teratomas should be distinguished from other cervical masses as:

- Hemangiomas

- Lymphangiomas

- Goiter.

The sonographic and developmental characteristics of a teratoma make the distinction very easy (Table 2 ).

\section{Prognosis}

The main factors that influence the immediate fetal prognosis are as follows:

- Preterm birth, due to polyhydramnios or iatrogenic

- Perinatal death, due to failure in establishing airway at birth.
Table 2: Differential diagnosis of cervical teratoma

\begin{tabular}{ll}
\hline Tumor & Characteristics \\
\hline Hemangioma & $\begin{array}{l}\text { Homogeneously echogenic or mixed cystic and } \\
\text { solid appearance with typical blood flow } \\
\text { distribution }\end{array}$ \\
Goiter & $\begin{array}{l}\text { Bilobed anterior neck mass adjacent to the } \\
\text { midline, solid-mixed-cystic-like appearance }\end{array}$ \\
Teratoma & $\begin{array}{l}\text { Well-defined, broad-based mass of the antero- } \\
\text { lateral portion of the neck, hyperextension of the } \\
\text { neck, partially cystic, partially solid with } \\
\text { echogenic reflections, polyhydramnios }\end{array}$ \\
\hline
\end{tabular}

Even when anticipated by the ultrasound, the procedure may be extremely difficult, as there is an important degree of tracheal deviation. The size of the teratoma is not necessarily predictive of this complication, as small tumors may be associated with an important alteration of the upper airway anatomy.

\section{Management}

The anterior localization and the semisolid appearance of these tumors can provoke an upper airway obstruction, which is the most urgent neonatal emergency, requiring immediate intervention. When anticipated by ultrasound, the necessary equipment can be mobilized at the time of the cesarean section to deal with these respiratory difficulties.

In small tumors, emergency tracheotomy may secure adequate ventilatory support.

Recurrence risk is absent. These tumors are strictly sporadic.

In Figures 4A to $\mathrm{C}$, the authors show a recent case of a large cervical teratoma (ultrasound and postnatal image). The baby died because the maternity unit was not aware of the diagnosis prior to delivery.

\section{Hemangioma/Lymphangioma}

Hemangiomas and lymphangiomas are tumors derived from the endothelial tissue of blood vessels or lymphatic vessels. They may develop anywhere in the body, but in the antenatal life and the first years they show a predisposition for the head, neck and axillary area. Even though hemangiomas and lymphangiomas originate from different vascular structures, they have common pathological and sonographic features, which explain why they are discussed together.

These vascular tumors are the most common tumors in the first three years of life, most of them (90\%) being present at birth or in the first days/months and some of them are diagnosed antenatally. ${ }^{39}$ 


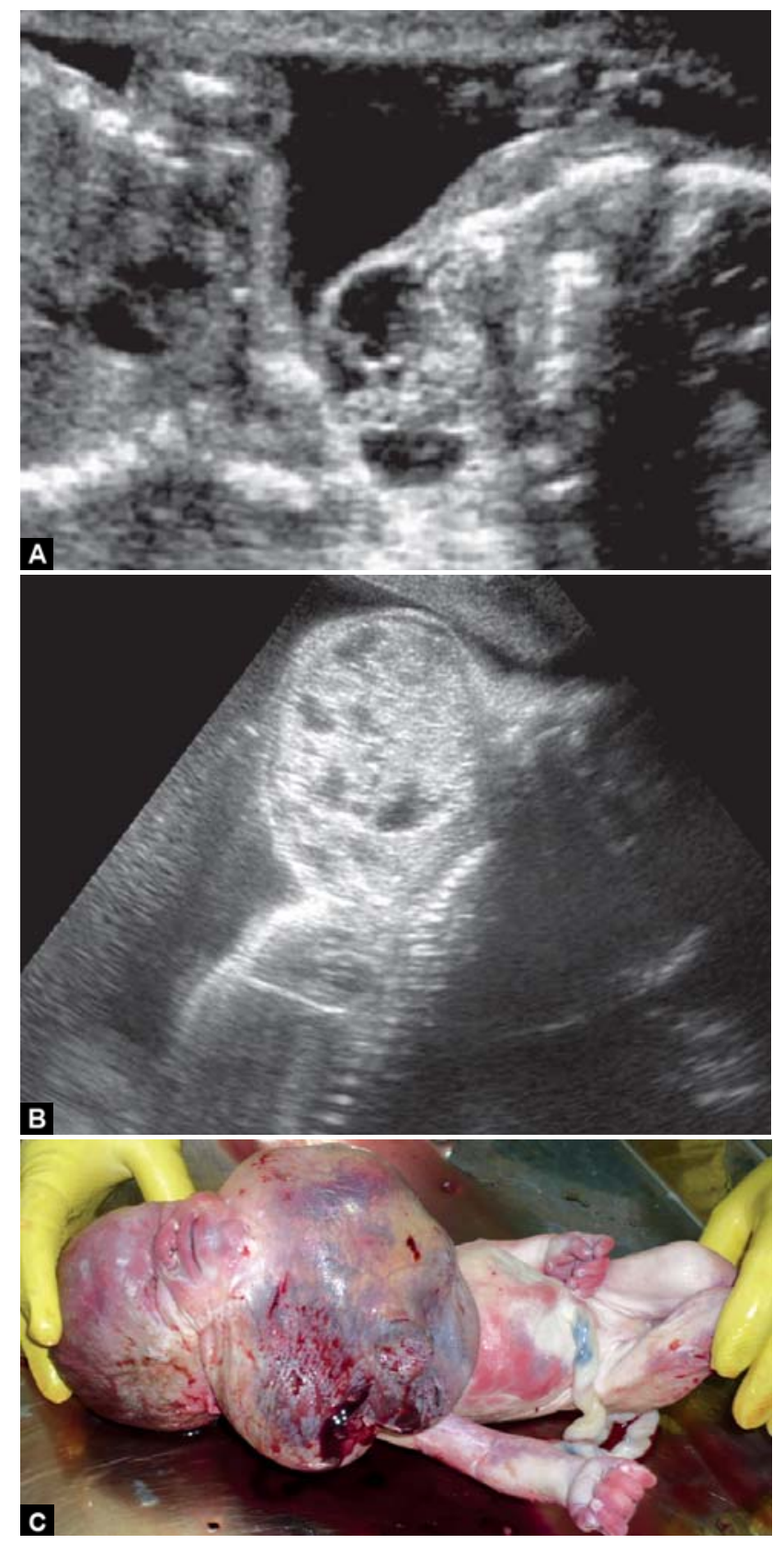

Figs 4A to C: Large teratoma. Ultrasound with hyperextended body and immediate postnatal aspect. Courtesy: Dr Cringu Lonescu

They affect up to $5 \%$ of infants, with a threefold higher rate for girls. It is difficult to estimate the true incidence of hemangiomas and the reported numbers vary from 15 to $10 \%{ }^{40}$

The incidence of hemangiomas is increased in preterm infants. The most significant risk factor appears to be lowbirth-weight. ${ }^{41}$

Multiple hemangiomas more commonly occur in products of multiple gestations. ${ }^{41}$

\section{Pathology}

Hemangiomas are the result of vascular endothelial proliferation. They have a predilection for the head and neck, although they can occur anywhere in the skin, mucous membranes, or internal organs. Hemangiomas range in size from a few millimeters to many centimeters in diameter. They may be superficial, deep or combined (compound hemangiomas).

Superficial hemangiomas present as a red papule, nodule, or plaque elevated above clinically normal skin. They are not detected antenatally. These are also called strawberry or capillary hemangiomas.

Cavernous hemangiomas are deep, subcutaneous tumors and their structure consists of vascular lakes, blood collections with low velocity flow. The hemangioma is typically a raised, skin-colored nodule, which often has a bluish hue with or without central telangiectatic patch. The name 'cavernous' hemangiomas, is erroneously used to describe venous malformations and is thus best avoided.

Hemangiomas characteristically undergo a growth (proliferative) phase that is generally rapid for the first several months. Slow proliferation can continue for the first 6 to 12 months.

The proliferative phase is followed by a spontaneous involution phase that typically begins after one year and lasts a variable number of years. Superficial hemangiomas typically enter the involution stage earlier than deep hemangiomas.

Lymphangiomas originated from the lymphatic vessels and develop in the axilla and neck. As for cavernous hemangiomas, it is difficult to say, if lymphangiomas are a lymphatic tumor or, more likely, a lymphatic drainage malformation.

\section{Diagnosis}

Both hemangiomas and lymphangiomas may be large size tumors, which makes the prenatal diagnosis easy. There are reports of first-trimester detection. ${ }^{42}$

Hemangiomas are solid or mixed solid and cystic tumors, with important vascularization (Fig. 5). Due to the low

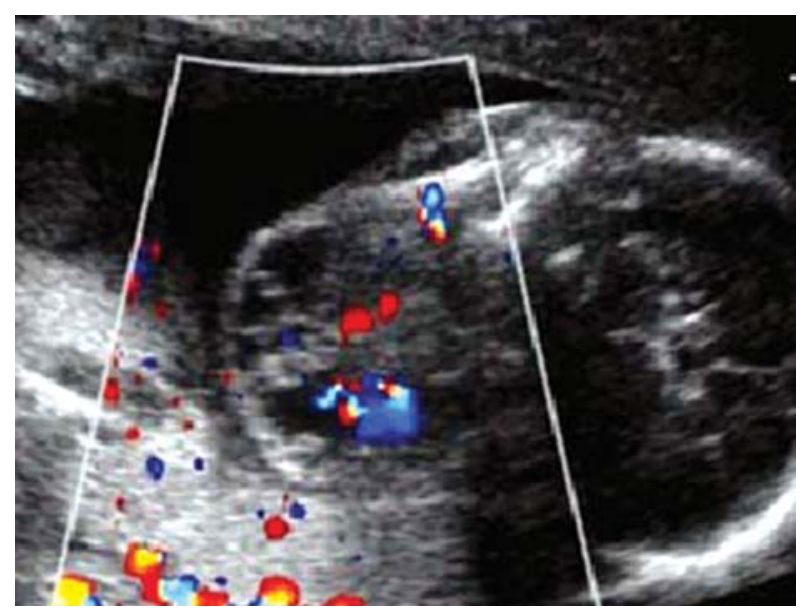

Fig. 5: Cervical hemangioma: A mixed solid-cystic tumor with marked vascularization 
velocity of the blood flow, power Doppler may be more useful than color Doppler. Even though the lesion is benign it may be fatal in cases with large tumors where congestive heart failure and hydrops may occur.

\section{Associated Anomalies}

The examiner has to be aware that in many cases the lesions are multiple. The presence of superficial hemangiomas may herald associated, visceral tumors. Multifocal hepatic hemangiomas most commonly occur in the presence of multiple skin hemangiomas and are probably most often asymptomatic. Rarely, multifocal hepatic hemangiomas can have large vessel shunts that result in heart failure.

The Klippel-Trenaunay-Weber syndrome is an association between vascular anomalies, such as lymphangiomas and limb hypertrophy.

Posterior fossa malformations, hemangiomas, arterial anomalies, coarctation of the aorta and other cardiac defects and eye abnormalities (PHACE) syndrome (MIM 606519) is defined by the presence of a large, segmental hemangioma, usually on the face, in association with one or more congenital malformations, most commonly structural or cerebrovascular anomalies of the brain.

\section{Management}

Involution is part of the natural history and only a limited number of cases will require further intervention. The involution rate is about $10 \%$ per year, so that about $90 \%$ of the hemagiomas will have disappeared by the age of 9 years. ${ }^{43}$ The parents have to be aware, though, that complete involution may be associated with lesions of the overlying skin, such as scarring, atrophy, redundant skin, discoloration and telangiectasias.

Medical treatment consists of corticosteroids and interferon.

Persisting hemangiomas and lymphangiomas may require laser ablation or surgical removal.

\section{Recurrence}

Although most hemangiomas occur sporadically, familial transmission in an autosomal dominant fashion has been reported.

\section{Cervical Chondrocutaneous Branchial Remnants}

Branchial remnants are developmental anomalies of the four pairs of branchial arches. These remnants may be cysts, fistula and skin tags, chondrocutaneous vestiges. Cervical chondrocutaneous branchial remnants are usually embedded in the anterior border of the sternocleidomastoid muscle and appear as skin tags. They probably originate from the second branchial arch.

\section{Diagnosis}

Depending on the size of the lesion, the brachial remnants may be visible antenatally. Skin tags are detected by ultrasound, as they are echogenic and elongated.

A clinical study following 20 children over a period of 13 years ${ }^{44}$ found that these lesions are more commonly found on the left side than the right and in boys rather than the girls.

\section{Associated Anomalies}

Associated anomalies are common, found in 70 to $80 \%$ of the cases.

They include anomalies of the auditory, respiratory, gastrointestinal, genitourinary, cardiovascular, musculoskeletal and visual systems. Therefore, it is essential that the detection of a skin tag, especially when located in the cervical region, should prompt for a detailed anatomical survey.

\section{Differential Diagnosis}

- Branchial cyst/fistula

- Thyroglossal cyst/fistula

- Hemangioma

- Dermoid tumor

- Goldenhar syndrome.

Regarding the occipital encephalocele and iniencephaly, even though they represent major anomalies that affect the cervical and cephalic area, from a developmental point of view they are part of the neural tube defects spectrum and should be considered, as such especially from a prognosis point of view.

\section{REFERENCES}

1. Malone FD, Ball RH, Nyberg DA, et al. First-trimester septated cystic hygroma. Prevalence, natural history and pediatric outcomes. Obstet Gynecol 2005;106(2):288-94.

2. Molina FS, Avgidou K, Kagan KO, et al. Cystic hygromas, nuchal edema, and nuchal translucency at 11 to 14 weeks of gestation. Obstet Gynecol 2006;107(3):678-83.

3. Haak MC, Twisk JW, Bartelings MM, et al. Ductus venosus flow velocities in relation to the cardiac defects in first-trimester fetuses with enlarged nuchal translucency. Am J Obstet Gynecol 2003;188(3):727-33.

4. Simpson JM, Sharland GK. Nuchal translucency and congenital heart defects: Heart failure or not? Ultrasound Obstet Gynecol 2000;16(1):30-36.

5. Haak MC, Twisk JW, Bartelings MM, et al. First-trimester fetuses with increased nuchal translucency do not show altered intracardiac flow velocities. Ultrasound Obstet Gynecol 2005;25(3):246-52. 
6. Martinez JM, Echevarria M, Gomez O, et al. Jugular vein and carotid artery blood flow in fetuses with increased nuchal translucency at 10-14 weeks' gestation. Ultrasound Obstet Gynecol 2003;22(5):464-69.

7. Nicolaides KH. First-trimester screening for chromosomal abnormalities. Semin Perinatol 2005;29(4):190-94.

8. Malone FD, Ball RH, Nyberg DA, et al. First-trimester septated cystic hygroma. Prevalence, natural history, and pediatric outcomes. Obstet Gynecol 2005;106(2):288-94.

9. Bronshtein M, Zimmer EZ, Blazer S. A characteristic cluster of fetal sonographic markers that are predictive of fetal Turner syndrome in early pregnancy. Am J Obstet Gynecol 2003;188(4):1016-20.

10. Graesslin O, Derniaux E, Alanio E, et al. Characteristics and outcome of fetal cystic hygroma diagnosed in the first trimester. Acta Obstet Gynecol Scand 2007;86(12):1442-46.

11. Mangione R, Guyon F, Taine L, et al. Pregnancy outcome and prognosis in fetuses with increased first-trimester nuchal translucency. Fetal Diagn Ther 2001;16(6):360-63.

12. Kagan KO, Gazzoni A, Sepulveda-Gonzalez G, et al. Discordance in nuchal translucency thickness in the prediction of severe twin-to-twin transfusion syndrome. Ultrasound Obstet Gynecol 2007;29(5):527-32.

13. Senat MV, Bussieres L, Couderc S, et al. Long-term outcome of children born after a first-trimester measurement of nuchal translucency at the 99th percentile or greater with normal karyotype: A prospective study. Am J Obstet Gynecol 2007;196(1):53e1-6.

14. Mehta PS, Mehta SJ, Vorherr H. Congenital iodide goiter and hypothyroidism: A review. Obstet Gyncol Surv 1983;38: 237-47.

15. Muir A, Daneman D, Daneman A, et al. TI. Thyroid scanning, ultrasound, and serum thyroglobulin in determining the origin of congenital hypothyroidism. Am J Dis Child 1988;142: 214-16.

16. Pohlenz J, Rosenthal IM, Weiss RE, et al. Congenital hypothyroidism due to mutations in the sodium/iodide symporter. Identification of a nonsense mutation producing a downstream cryptic 3' splice site. J Clin Invest 1998;101: 1028-35.

17. Everett LA, Morsli H, Wu DK, et al. Expression pattern of the mouse ortholog of the Pendred's syndrome gene (Pds) suggests a key role for pendrin in the inner ear. Proc Natl Acad Sci USA 1999;96:9727-32.

18. van de Graaf SA, Ris-Stalpers C, Veenboer GJ, et al. A premature stopcodon in thyroglobulin messenger RNA results in familial goiter and moderate hypothyroidism. J Clin Endocrinol Metab 1999;84:2537-42.

19. Brown RS, Bellisario RL, Mitchell E, et al. Detection of thyrotropin binding inhibitory activity in neonatal blood spots. J Clin Endocrinol Metab 1993;77:1005-08.

20. Paschke R, Ludgate $M$. The thyrotropin receptor in thyroid diseases. N Engl J Med 1997;337(23):1675-81.

21. Mastorakos G, Mitsiades NS, Doufas AG, et al. Hyperthyroidism in McCune-Albright syndrome with a review of thyroid abnormalities sixty years after the first report. Thyroid 1997;7:433-39.

22. Ranzini AC, Ananth CV, Smulian JC, et al. Ultrasonography of the fetal thyroid: Nomograms based on biparietal diameter and gestational age. J Ultrasound Med 2001;20:613-17.
23. Ho SS, Metreweli C. Normal fetal thyroid volume. Ultrasound Obstet Gynecol 1998;II:118-22.

24. Luton D, Fried D, Sibony O, et al. Assessment of fetal thyroid function by colored Doppler echography. Fetal Diagn Ther 1997;12(1):24-27.

25. Polak M, Le Gac I, Vuillard E, et al. Fetal and neonatal thyroid function in relation to maternal Graves' disease. Best Pract Res Clin Endocrinol Metab 2004;18:289-302.

26. Marín RC, Bello-Muñoz JC, Martínez GV, et al. Use of 3-dimensional sonography for prenatal evaluation and followup of fetal goitrous hypothyroidism. J Ultrasound Med 2010;29:1339-43.

27. Goldstein I, Lockwood C, Belanger K, et al. Ultrasonographic assessment of gestational age with the distal femoral and proximal tibial ossification centers in the third trimester. Am J Obstet Gynecol 1988;158:127-30.

28. Ribault V, Castanet M, Bertrand AM, et al. Experience with intra-amniotic thyroxine treatence with intraamniotic thyroxine treatroidism in 12 cases. J Clin Endocrinol Metab 2009;94(10):3731-39.

29. Olivieri A, Stazi MA, Mastroiacovo P, et al. A population-based study on the frequency of additional congenital malformations in infants with congenital hypothyroidism: Data from the Italian Registry for Congenital Hypothyroidism (1991-1998). J Clin Endocrinol Metab 2002;87(2):557-62.

30. Castanet M, Park SM, Smith A, et al. A novel loss-of-function mutation in TTF-2 is associated with congenital hypothroidism, thyroid agenesis and cleft palate. Hum Mol Genet 2002; 11(17):2051-59.

31. Doyle DA, Gonzalez I, Thomas B, et al. Autosomal dominant transmission of congenital hypothyroidism, neonatal respiratory distress, and ataxia caused by a mutation of NKX2.1. J Pediatr 2004;145(2):190-93.

32. Polak M, Van Vliet G. Therapeutic approach of fetal thyroid disorders. Horm Res Paediatr 2010;74(1):1-5.

33. Luton D, Le Gac I, Vuillard E, et al. Management of Graves' disease during pregnancy: The key role of fetal thyroid gland monitoring. J Clin Endocrinol Metab 2005;90(11):6093-98.

34. Foulds N, Walpole I, Elmslie F, et al. Carbimazole embryopathy: an emerging phenotype. Am J Med Genet 2004;132A:130-35.

35. Isaacs H. Perinatal neoplasms: A report of 110 cases. Pediatr Pathol 1985;3:165-216.

36. Teal LN, Antuaco TL, Jimenez JF, et al. Fetal teratomas: Antenatal diagnosis and clinical management. J Clin Ultra sound 1988;16(5):329-36.

37. Catte LD, De Backer A, Goosens A, et al. In: Teratoma, neck, Jeanry P (Ed). Available at: http://www.thefetus. net. Accessed September 3, 2002.

38. Jordan RB, Gauderer MW. Cervical teratomas: An analysis. Literature review and proposed classification. J Pediatr Surg 1988;23:583-91.

39. Clavelli A. Lymphangioma, case of day. Jeanty P. Available at: http://www.thefetus.net. Accessed August 1999.

40. Kilcline C, Frieden IJ. Infantile hemangiomas: How common are they? A systematic review of the medical literature. Pediatr Dermatol 2008;25(2):168-73. 
41. Haggstrom AN, Drolet BA, Baselga E, et al. Prospective study of infantile hemangiomas: Demographic, prenatal and perinatal characteristics. J Pediatr 2007;150(3):291-94.

42. Viora E, Grassi Pirrone P, Comoglio F, et al. Ultrasonographic detection of fetal craniofacial hemangioma: Case report and review of the literature. Ultrasound Obstet Gynecol 2000;15: 431-34.

43. Metry DW, Hebert AA. Benign cutaneous vascular tumors of infancy: When to worry, what to do? Arch Dermatol 2000;136:905.

44. Atlan G, Egerszegi EP, Brochu P, et al. Cervical chrondrocutaneous branchial remnants. Plast Reconstr Surg 1997;100(1):32-39.

\section{ABOUT THE AUTHORS}

\section{Radu Vladareanu (Corresponding Author)}

Department of Obstetrics and Gynecology, Elias Emergency University Hospital, Bucharest, Romania, e-mail: vladareanu@ gmail.com

\section{Mona Zvanca}

Department of Obstetrics and Gynecology, Elias Emergency University Hospital, Bucharest, Romania

\section{Cristian Andrei}

Department of Obstetrics and Gynecology, Elias Emergency University Hospital, Bucharest, Romania 